\title{
Sex difference in oral disease of millet agriculturalists from the Take-vatan lineage of the recent Bunun tribe of Taiwan
}

\author{
Kenji OKAZAKI $^{1 *}$, TsAI Pei-Ying ${ }^{2}$, Lu Kuo-Shyan ${ }^{1}$ \\ ${ }^{1}$ Graduate Institute of Anatomy and Cell Biology, College of Medicine, National Taiwan University, Taipei 100, Taiwan \\ ${ }^{2}$ Museum of Medical Humanities, National Taiwan University, Taipei 100, Taiwan
}

Received 7 August 2012; accepted 22 February 2013

\begin{abstract}
Biological anthropologists have repeatedly demonstrated a sex difference of caries prevalence in past societies and have often ascribed this difference to cultural factors related to the sexual division of labor, as well as to biological factors stemming from the female reproductive function. Even though archaeological and historical evidence can hint at the prevailing living conditions, they are not detailed enough to confirm the cultural factors influencing oral disease. For this, skeletal remains in which the prevailing subsistence patterns have been documented by cultural anthropologists must be studied. This study demonstrates sex-specific oral disease prevalence (caries, antemortem tooth loss, periapical abscess, alveolar resorption, and calculus accretion) as well as degree of dental attrition, using the recent Bunun skeletal assemblage, one of the Taiwanese aboriginals. During Japanese rule, cultural anthropologists recorded that the staple product of the Bunun tribe was foxtail millet. Males were responsible for cultivation and hunting, while females were responsible for gathering and preparing foods. The results of this study showed the relatively high morbidity of oral disease, except periapical abscess, regardless of sex. The frequency of females suffering caries and alveolar resorption was significantly greater compared to that of males, and the inverse was true for calculus. Taking into account the fact that the Bunun tribe depend greatly on vegetable foods and smoke heavily, their high morbidity of oral disease is understandable. The combination of their higher morbidity in alveolar resorption and calculus is comparable to the Southeast Asian groups chewing betel nuts documented in previous studies. The sex-specific caries prevalence is believed to be related to the Bunun's typical and strict sexual division of labor. The inconsistency of the sex difference patterns between alveolar resorption and calculus might be related to the multifactorial origin of the alveolar resorption.
\end{abstract}

Key words: Taiwanese aboriginal, sexual division of labor, dental caries, alveolar resorption, calculus

\section{Introduction}

Oral pathology is utilized by biological anthropologists worldwide as a method to assess diet and food-preparation techniques in past societies, because oral diseases are strongly related to subsistence patterns (e.g. Turner, 1979; Powell, 1985; Lukacs, 1989; Walker and Erlandson, 1986; Walker and Hewlett, 1990; Larsen, 1997; Pechenkina et al., 2002; Temple and Larsen, 2007; Oyamada et al., 2010). Calculations by Turner (1979) concerning average dental caries prevalence on the basis of a worldwide population study show a $1.3 \%$ rate of caries in a foraging economy, a $4.8 \%$ rate in a mixed economy, and a $10.4 \%$ rate in an agricultural economy. Lukacs (1989) proposed a dental pathology profile (DPP) as a standardized method for recording and reporting dental pathological conditions for comparative re-

* Correspondence to: Kenji Okazaki, Division of Morphological Analysis, Department of Anatomy, Faculty of Medicine, Tottori University, 86 Nishi-cho, Yonago 683-8503, Japan.

E-mail: ken_okz@med.tottori-u.ac.jp

Published online 4 July 2013

in J-STAGE (www.jstage.jst.go.jp) DOI: 10.1537/ase.130222 search. The variables in DPP are caries, antemortem tooth loss (AMTL), periapical abscess, alveolar resorption, calculus, severe attrition, enamel hypoplasia, and jaw robustness. The components of DPP shift from hunting-gathering to agricultural pursuits: intensive agriculturalists typically have higher frequencies of caries, calculus, alveolar resorption, and enamel hypoplasia, and lower frequencies of severe attrition (unless abrasive materials were mixed with foods during preparation), compared to hunter-gatherers. Huntergatherers do not necessarily have lower frequencies of AMTL or periapical abscess, because not only caries but also severe attrition can cause both pathologies. The relationship between subsistence pattern and human health, however, appears not to be straightforward. Several case studies have demonstrated that agricultural development is not accompanied by an increase in caries frequency in Southwest Europe and Southeast Asia (Lubell et al., 1994; Pietrusewsky and Douglas, 2001; Domett and Tayles, 2006; Oxenham et al., 2006).

The sex difference of oral pathology could provide additional clues about life in past societies. It is widely reported that females generally display worse dental health, especially caries prevalence, than males in past and present contexts 
(Walker and Erlandson, 1986; Walker and Hewlett, 1990; Larsen, 1997; Fujita et al., 2007; Lukacs and Thompson, 2008; Temple, 2011). One factor contributing to this sex difference could be female life history connected with reproductive ecology: cariogenic oral environments could be produced by changes in saliva composition and volume accompanying changes in estrogen levels triggered by menstruation and pregnancy (Lukacs and Largaespada, 2006; Lukacs and Thompson, 2008). In addition, two cultural factors may explain the sex difference in caries prevalence, both of which are related to the sexual division of labor in past societies. First, females tend to consume a greater amount of carbohydrate-rich foods, which is thought to be more cariogenic, while males tend to consume greater amounts of meat products, which are less cariogenic (Larsen, 1997). Second, females more frequently access foods during food procurement and production (Walker and Hewlett, 1990).

The variation of oral disease prevalence needs to be further examined, especially by studying recent groups of pre-industrialized societies whose lifestyle has been minutely documented by cultural anthropologists. In this case, more reliable and detailed discussion on the relationship between oral disease prevalence and a society's lifestyle is possible. The purpose of this study is to document the oral health of the recent (early to mid twentieth century) Bunun tribe, a Taiwanese aboriginal people, who relied on millet agriculture and hunting-gathering. This study specifically aims to examine the relationship between the oral disease prevalence and the tribe's subsistence pattern, including the sexual division of labor.

\section{Materials}

\section{Samples}

A total of 850 teeth and 1241 alveoli from 44 individuals from the cemetery around Bahoan village, Wanrong, Hualien county in Taiwan were included in the study (Table 1). These individuals were interred between 1943 and 1957 according to the record of burial markers and the memory of the villagers. These skeletal remains were excavated by Tsai His-Kuei and are curated at the Department of Anatomy and Cell Biology, College of Medicine, National Taiwan University (Doi et al., 2008).

Bahoan village is surrounded by the Malangou and Hudie valleys to the north and Hutou Mountain to the south (Figure 1). The postal address is 979 Wanrong, Hualian county. The village was built under the order of the
Governor-General of Taiwan (a department of the Empire of Japan) for the enforced migration of the Bunun people between 1919 and 1921. Most of the villagers came from the Take-vatan lineage of the Bunun people, who had previously resided deep in the mountains of Middle Taiwan (Wanrong administration, personal communication).

\section{Methods}

\section{Oral pathology}

The presence of AMTL, carious lesions, periapical abscess, alveolar resorption, and calculus accretion, and the degree of dental wear were examined in each tooth using a $10 \times$ magnifying lens and a dental mirror in accordance with standards established by Lukacs (1989) and Hillson (1996, 2001). AMTL was defined as a completely closed alveolar socket with reduced alveolar height to a nearly closed alveolar socket with active bone formation (Lukacs, 1989; Pechenkina, personal communication). Carious lesions were identified based on enamel demineralization in stages that ranged from complete destruction of a tooth crown to pinprick-sized lesions (Lukacs, 1989; Hillson, 1996; Temple and Larsen, 2007). Carious lesions were classified into (1) occlusal surface, (2) interproximal surfaces, (3) smooth surfaces, (4) cervical, (5) root, and (6) large carious lesions (Buikstra and Ubelaker, 1994). Periapical abscesses originate as a chronic cyst and/or an infection in the pulp due to chronic cariogenesis, severe wear, or dental trauma. Because of the difficulty in differentiating between these factors (Dias and Tayles, 1997; Oxenham et al., 2006), only the presence or absence of periapical abscess was recorded (Lukacs, 1989). Alveolar resorption also has a multifactorial etiology (e.g. periodontal disease, caries, periapical abscess, and continuous eruption) (Hillson, 1996; Kaifu et al., 2003). Although making a correct diagnosis is difficult, the following definitions were all counted as affected: (1) slight: resorption confined to the alveolar crest with active bone formation or periodontal pocket or notch-like resorption of the alveolar crest; (2) moderate: horizontal or vertical bone loss limited to half of the length of the tooth root; 3 ) severe: horizontal or vertical bone loss reaching more than half of the length of the tooth root (Lukacs, 1989; Sakashita et al., 1997; Pechenkina, personal communication). Calculus accretion on tooth crowns and roots near the cervix was graded from small to large according to standards defined by Brothwell (1981). These three stages were all counted as affected in this study.

Given that dental wear plays an important etiology in oral

Table 1. Sex and age distribution of skeletal/dental assemblage analyzed in this study

\begin{tabular}{|c|c|c|c|c|c|c|c|c|c|c|c|c|c|c|c|c|c|c|}
\hline \multirow{2}{*}{$\begin{array}{c}\text { Catego- } \\
\text { ry }\end{array}$} & \multirow{2}{*}{$\begin{array}{l}\text { Num- } \\
\text { ber }\end{array}$} & \multicolumn{8}{|c|}{ Observed teeth } & \multicolumn{8}{|c|}{ Examined alveoli } & \multirow{2}{*}{$\begin{array}{c}\text { Mean } \\
\text { age } \\
\text { (years) }\end{array}$} \\
\hline & & Ant N & Ant $\%$ & Pre N & Pre \% & Mol N & Mol \% & Total $\mathrm{N}$ & NTotal \% & Ant $N$ & Ant $\%$ & Pre N & Pre \% & Mol N & $\mathrm{Mol} \%$ & Total N & NTotal $\%$ & \\
\hline Male & $26(20)$ & 157 & 50.3 & 165 & 79.3 & 210 & 67.3 & 532 & 63.9 & 285 & 91.3 & 192 & 92.3 & 263 & 84.3 & 740 & 88.9 & 35.4 \\
\hline Female & $18(11)$ & 105 & 48.6 & 97 & 67.4 & 116 & 53.7 & 318 & 55.2 & 197 & 91.2 & 130 & 90.3 & 174 & 80.6 & 501 & 87.0 & 33.7 \\
\hline All & $44(31)$ & 262 & 49.6 & 262 & 74.4 & 326 & 61.7 & 850 & 60.4 & 482 & 91.3 & 322 & 91.5 & 437 & 82.8 & 1241 & 88.1 & 34.7 \\
\hline
\end{tabular}

Abbreviations: Ant, incisors and canines; Pre, premolars; Mol, molars; N, the number of observed teeth or examined alveoli; \%, [the number of observed teeth or examined alveoli/the maximum number of teeth or alveoli (in the case that they are perfectly preserved)] $\times 100$. The figures in parentheses show the number of individuals aged 30-39 years. 


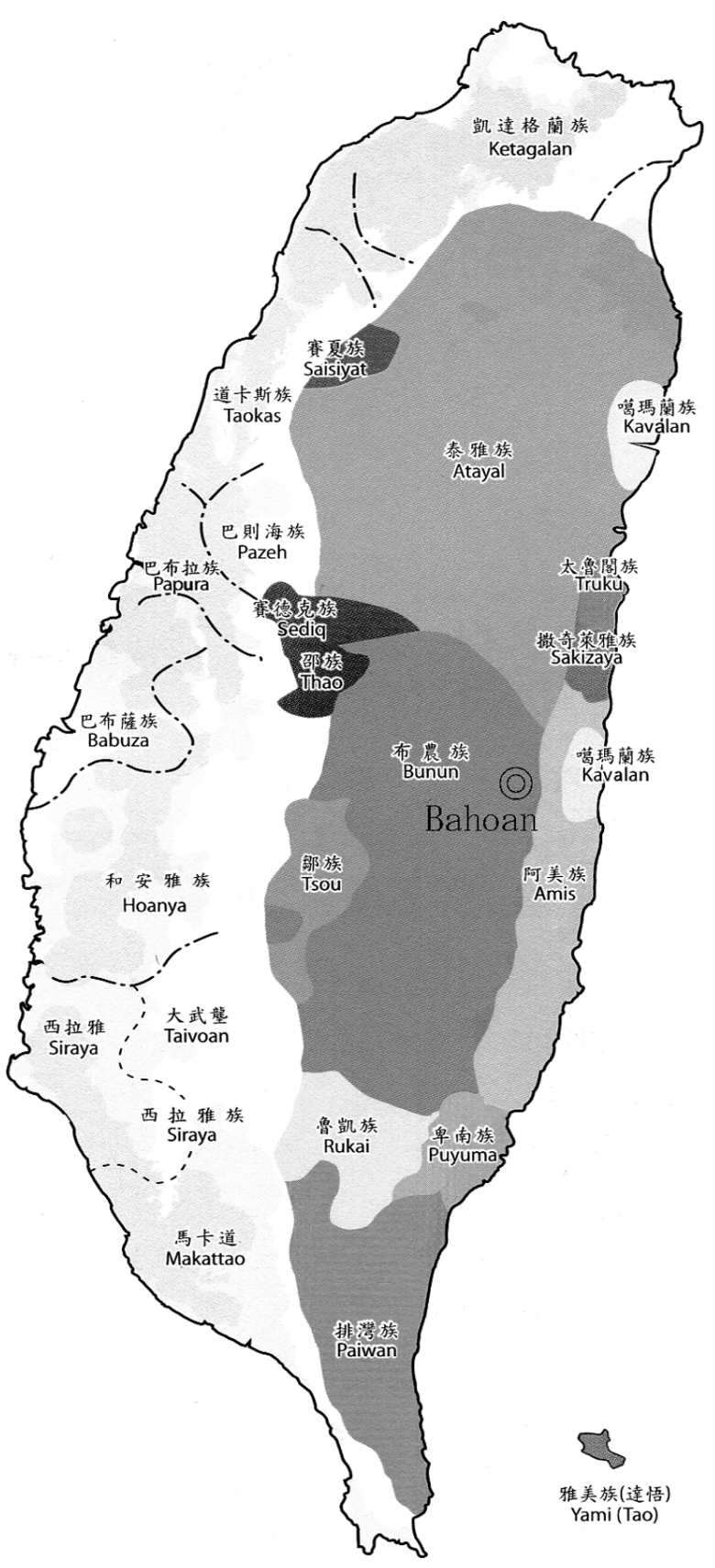

Figure 1. Map showing the geographic locations of Bahoan village and the distribution of the residence of the Taiwanese aboriginals.

pathology, it is important to compare a measure of this variable among the samples (Lukacs, 1989). Tooth wear was scored according to standards established by Buikstra and Ubelaker (1994) using primary scores for the anterior and premolar teeth and summary scores derived from all quadrants of the molar teeth.

\section{Controlling for biological sex and age}

Sex was determined based on pelvic morphology (Phenice, 1969; Bruzek, 2002; Walker, 2005). Cranial morphological traits were used when pelvic bones were not recovered (Buikstra and Ubelaker, 1994). Adult age was estimated based on age-related changes of the morphology of pubic symphysis and auricular surfaces (Todd, 1920; Meindl et al., 1985; Lovejoy et al., 1985), and cranial suture closure was used to estimate age where pelvic bones were unavailable (Meindl and Lovejoy, 1985). The frequencies of pathological conditions should be calculated for each age stage group, because these pathologies are degenerative. Only sex difference was examined after the age distribution was compared between the sexes, since the sample size was not large enough to determine the statistical significance of sex difference for each age group in this study.

\section{Calculations and statistical treatments}

The ratio of observable teeth was lower in the anterior dentition, partly because of taphonomic factors influencing tooth preservation (Table 1). Therefore, the 'tooth count manner' was used for calculation to avoid any bias caused by imbalance among teeth segments (Douglas, 2006). That is, the prevalence of carious teeth, calculus, and advanced attrition was calculated as (affected teeth/observable teeth) $\times 100$. The prevalence of AMTL, pericapical abscess, and alveolar resorption was calculated as (affected alveoli/ examined alveoli) $\times 100$.

Sex differences of frequencies calculated by the tooth count manner were examined by Yates' chi-squared test. Sex differences of the age distribution and the degree of dental wear were examined by the Mann-Whitney U-test. These analyses were performed using the computer program package Statistica (StatSoft Inc., 1996).

\section{Results}

The age distribution did not differ significantly between the sexes according to the statistical analysis (Table 1). The majority of males and females were in their 30s (male, 20; female, 11), followed by people in their 20s (male, 2; female, 4 ) or 40 s (male, 4 ; female, 2 ) and one female aged about 17 years. Thus, the commingling of individuals of different ages could lead to the minimum bias for comparing the sexes in the following analysis.

Table 2 and Figure 2 show the results of oral disease. The prevalence of dental caries was very high, $14.1 \%$ in total. It was the highest in the molar compartment and the lowest in the anterior compartment (Table 2), which matched the clinical data (Hillson, 1996). The dental caries prevalence of females was much greater than that of males. The sex difference was statistically significant in the molar compartment and in total (Table 2).

The AMTL prevalence was also high, $11.2 \%$ in total. It was the highest in the anterior compartment and the lowest in the premolar compartment (Table 2). No statistically significant sex difference was found. The highest AMTL prevalence in the anterior compartment should be attributed to the cultural tooth extraction of the upper incisors and canines. The cultural tooth extraction was observed in 26 of 40 individuals $(65.0 \%)$, and the combination of upper lateral incisors and canines was the greatest among the extraction combination (found in 17 of 26 individuals).

The periapical abscess prevalence was very low, $1.0 \%$ in 
Table 2. Oral disease prevalence for sex and tooth compartment

\begin{tabular}{|c|c|c|c|c|c|c|c|c|c|c|c|c|c|c|c|c|c|c|c|c|}
\hline & \multicolumn{4}{|c|}{ Caries } & \multicolumn{4}{|c|}{ Antemortem tooth loss } & \multicolumn{4}{|c|}{ Periapical abscess } & \multicolumn{4}{|c|}{ Alveolar resorption } & \multicolumn{4}{|c|}{ Calculus } \\
\hline & A & $\mathrm{O}$ & $\%$ & $\begin{array}{l}\text { Sex } \\
\text { diff }\end{array}$ & A & $\mathrm{O}$ & $\%$ & $\begin{array}{l}\text { Sex } \\
\text { diff }\end{array}$ & A & $\mathrm{O}$ & $\%$ & $\begin{array}{l}\text { Sex } \\
\text { diff }\end{array}$ & A & $\mathrm{O}$ & $\%$ & $\begin{array}{l}\text { Sex } \\
\text { diff }\end{array}$ & A & $\mathrm{O}$ & $\%$ & $\begin{array}{l}\text { Sex } \\
\text { diff }\end{array}$ \\
\hline \multicolumn{21}{|l|}{ Male } \\
\hline Ant & 6 & 157 & 3.8 & $\mathrm{n}$ & 55 & 283 & 19.4 & $\mathrm{n}$ & 3 & 230 & 1.3 & $\mathrm{n}$ & 7 & 230 & 3.0 & $* *$ & 147 & 156 & 94.2 & $* *$ \\
\hline Pre & 16 & 165 & 9.7 & $\mathrm{n}$ & 7 & 192 & 3.6 & $\mathrm{n}$ & 2 & 185 & 1.1 & $\mathrm{n}$ & 24 & 185 & 13.0 & $\mathrm{n}$ & 144 & 162 & 88.9 & $*$ \\
\hline Mol & 42 & 210 & 20.0 & * & 21 & 261 & 8.0 & $\mathrm{n}$ & 2 & 242 & 0.8 & $\mathrm{n}$ & 49 & 242 & 20.2 & $* *$ & 183 & 206 & 88.8 & * \\
\hline Total & 64 & 532 & 12.0 & $*$ & 83 & 736 & 11.3 & $\mathrm{n}$ & 7 & 657 & 1.1 & $\mathrm{n}$ & 80 & 657 & 12.2 & $* *$ & 474 & 524 & 90.5 & $* *$ \\
\hline \multicolumn{21}{|l|}{ Female } \\
\hline Ant & 5 & 105 & 4.8 & & 29 & 197 & 14.7 & & 0 & 168 & 0.0 & & 19 & 168 & 11.3 & & 76 & 100 & 76.0 & \\
\hline Pre & 13 & 97 & 13.4 & & 6 & 130 & 4.6 & & 2 & 124 & 1.6 & & 24 & 124 & 19.4 & & 73 & 93 & 78.5 & \\
\hline Mol & 38 & 116 & 32.8 & & 21 & 174 & 12.1 & & 2 & 153 & 1.3 & & 55 & 153 & 35.9 & & 89 & 113 & 78.8 & \\
\hline Total & 56 & 318 & 17.6 & & 56 & 501 & 11.2 & & 4 & 445 & 0.9 & & 98 & 445 & 22.0 & & 238 & 306 & 77.8 & \\
\hline \multicolumn{21}{|l|}{ All } \\
\hline Ant & 11 & 262 & 4.2 & & 84 & 480 & 17.5 & & 3 & 398 & 0.8 & & 26 & 398 & 6.5 & & 223 & 256 & 87.1 & \\
\hline Pre & 29 & 262 & 11.1 & & 13 & 322 & 4.0 & & 4 & 309 & 1.3 & & 48 & 309 & 15.5 & & 217 & 255 & 85.1 & \\
\hline Mol & 80 & 326 & 24.5 & & 42 & 435 & 9.7 & & 4 & 395 & 1.0 & & 104 & 395 & 26.3 & & 272 & 319 & 85.3 & \\
\hline Total & 120 & 850 & 14.1 & & 139 & 1237 & 11.2 & & 11 & 1102 & 1.0 & & 178 & 1102 & 16.2 & & 712 & 830 & 85.8 & \\
\hline
\end{tabular}

Abbreviations: A, the number of affected teeth; $\mathrm{O}$, the number of observed teeth; $\%,(\mathrm{~A} / \mathrm{O}) \times 100$; Sex diff, $P$ value for sex difference. Significance is set at $P<0.05$ for sex difference: **, $P<0.01 ; *, P<0.05 ; \mathrm{n}, P>0.05$.

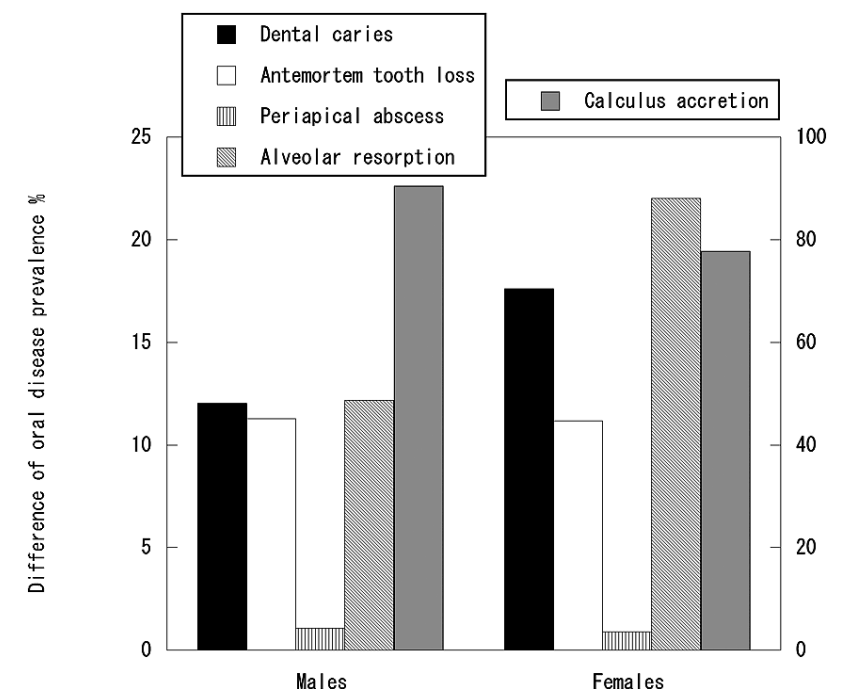

Figure 2. Percentage differences in oral disease prevalence among groups: dental caries, antemortem tooth loss, periapical abscess, alveolar resorption, and calculus accretion. The divisions of the scale on the right are for calculus accretion prevalence, while those on the left are for the other diseases.

total. The frequency was almost the same among the tooth compartments. No statistically significant sex difference was found.

The alveolar resorption prevalence was considerably high, $16.2 \%$ in total. The frequency was the highest in the molar compartment and the lowest in the anterior compartment (Table 2). The alveolar resorption prevalence of females was much higher than that of males. The sex difference was statistically significant in the anterior and molar compartments, as well as in total (Table 2).

The calculus prevalence was also high, $85.8 \%$ in total. The frequency was almost the same among the tooth com-
Table 3. Distribution of the frequency of dental caries for the location

\begin{tabular}{|c|c|c|c|c|c|c|}
\hline & \multicolumn{2}{|c|}{ Male } & \multicolumn{2}{|c|}{ Female } & \multicolumn{2}{|c|}{ All } \\
\hline & $N$ & $\%$ & $N$ & $\%$ & $N$ & $\%$ \\
\hline Occlusal surface & 7 & 10.9 & 6 & 10.7 & 13 & 10.8 \\
\hline Interproximal surface & 33 & 51.6 & 20 & 35.7 & 53 & 44.2 \\
\hline Smooth surface & 2 & 3.1 & 2 & 3.6 & 4 & 3.3 \\
\hline Cervical surface & 12 & 18.8 & 20 & 35.7 & 32 & 26.7 \\
\hline Root & 7 & 10.9 & 3 & 5.4 & 10 & 8.3 \\
\hline Large & 3 & 4.7 & 5 & 8.9 & 8 & 6.7 \\
\hline Total & 64 & - & 56 & & 120 & - \\
\hline
\end{tabular}

Abbreviation: $N$, number of affected teeth; \%, (Local $N /$ Total N) $\times 100$.

partments. The calculus prevalence of males was higher than that of females. The sex difference was statistically significant in all tooth compartments (Table 2).

Table 3 shows the difference in dental caries prevalence by tooth location. The rate of dental caries on the interproximal surface was the highest $(44.2 \%)$, followed by dental caries on the cervical surface $(26.7 \%)$ and on the occlusal surface $(10.8 \%)$.

Table 4 shows the dental wear of the first and second molars. The Bunun assemblage shows relatively weak dental wear, compared to that of prehistoric groups (e.g. Neolithic Chinese documented by Pechenkina et al. (2002) and Okazaki et al. (in preparation)). No statistically significant sex difference was found.

\section{Discussion}

This study showed relatively high morbidity in dental caries, alveolar resorption, and calculus accretion, but not in periapical abscess (Table 2, Figure 2, Figure 3). The greatest prevalence of dental caries was observed on the interproximal and cervical surfaces (Table 3 ). The AMTL prevalence 
Table 4. Degree of dental attrition on molars for sex

\begin{tabular}{|c|c|c|c|c|c|c|c|c|c|c|c|c|c|c|c|c|}
\hline \multirow[b]{2}{*}{ Upper jaw } & \multicolumn{4}{|c|}{ RM1 } & \multicolumn{4}{|c|}{ LM1 } & \multicolumn{4}{|c|}{ RM2 } & \multicolumn{4}{|c|}{ LM2 } \\
\hline & $N$ & M & $\mathrm{SD}$ & $\begin{array}{l}\text { Sex } \\
\text { diff }\end{array}$ & $N$ & M & $\mathrm{SD}$ & $\begin{array}{l}\text { Sex } \\
\text { diff }\end{array}$ & $N$ & M & $\mathrm{SD}$ & $\begin{array}{l}\text { Sex } \\
\text { diff }\end{array}$ & $N$ & M & SD & $\begin{array}{l}\text { Sex } \\
\text { diff }\end{array}$ \\
\hline Male & 19 & 15.4 & 3.42 & \multirow{2}{*}{$\mathrm{n}$} & 19 & 15.7 & 4.25 & \multirow{2}{*}{$\mathrm{n}$} & 17 & 13.7 & 2.59 & \multirow{2}{*}{$\mathrm{n}$} & 17 & 14.3 & 3.62 & \multirow{2}{*}{$\mathrm{n}$} \\
\hline Female & 10 & 15.4 & 3.89 & & 11 & 13.9 & 3.08 & & 6 & 14.0 & 2.28 & & 11 & 12.3 & 3.07 & \\
\hline \multirow[b]{2}{*}{ Lower jaw } & \multicolumn{4}{|c|}{ RM1 } & \multicolumn{4}{|c|}{ LM1 } & \multicolumn{4}{|c|}{ RM2 } & \multicolumn{4}{|c|}{ LM2 } \\
\hline & $N$ & M & $\mathrm{SD}$ & $\begin{array}{l}\text { Sex } \\
\text { diff }\end{array}$ & $N$ & M & $\mathrm{SD}$ & $\begin{array}{l}\text { Sex } \\
\text { diff }\end{array}$ & $N$ & M & SD & $\begin{array}{l}\text { Sex } \\
\text { diff }\end{array}$ & $N$ & M & $\mathrm{SD}$ & $\begin{array}{l}\text { Sex } \\
\text { diff }\end{array}$ \\
\hline Male & 21 & 15.7 & 2.92 & & 23 & 15.7 & 3.45 & & 19 & 14.6 & 3.32 & & 20 & 14.9 & 3.21 & \\
\hline Female & 11 & 16.3 & 3.13 & $\mathrm{n}$ & 14 & 14.1 & 2.03 & $\mathrm{n}$ & 10 & 14.5 & 2.12 & $\mathrm{n}$ & 12 & 14.3 & 2.42 & $\mathrm{n}$ \\
\hline
\end{tabular}

Abbreviations: RM, right molar; LM, left molar; $N$, the number of observed teeth; M, mean; SD, standard deviation; Significance is set at $P<0.05$ between males and females (Mann-Whitney $U$-test): $\mathrm{n}, P>0.05$.

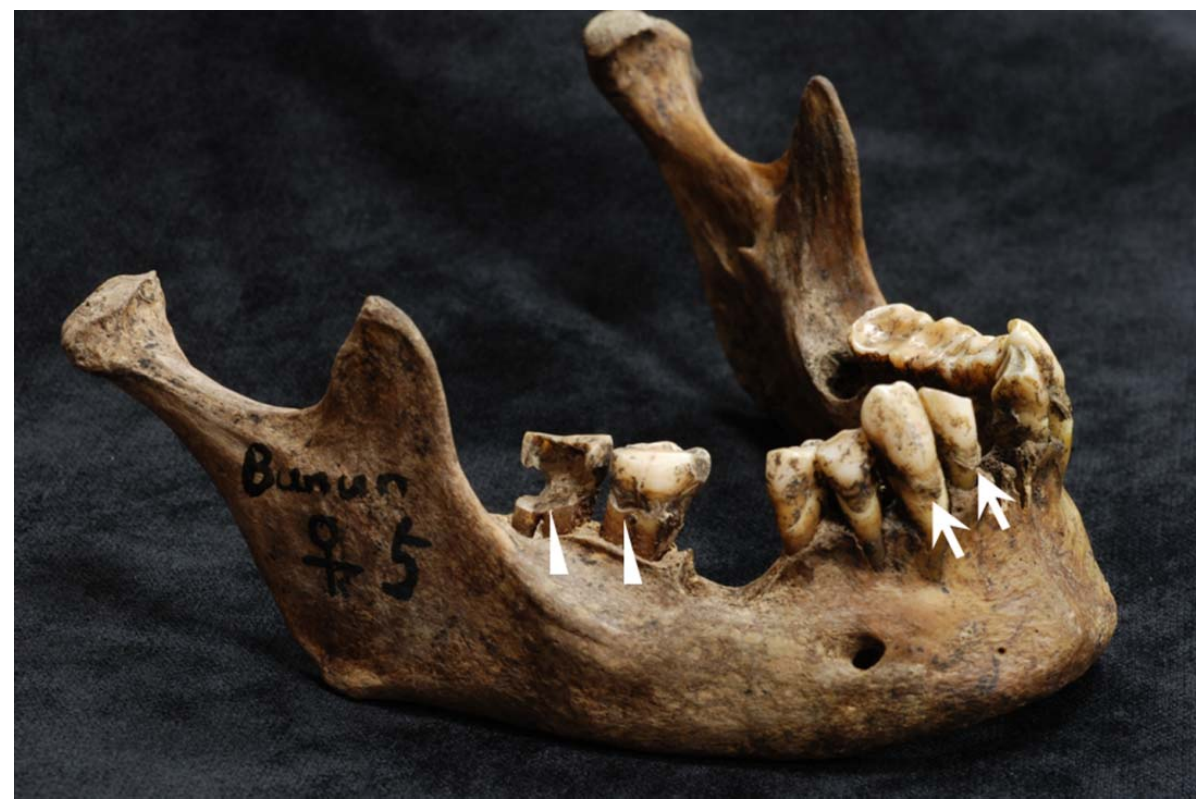

Figure 3. An example of oral diseases in an adult female (M5 individual) from the Bunun assemblage. The arrowheads indicate calculus accretion of the anterior teeth, while the triangles indicate dental caries of the molars. These molars also exhibit horizontal bone loss (Hillson, 1996).

was also relatively high, especially in the anterior tooth compartment (Table 2), due to the cultural tooth extraction (Nakahashi, 2008; this study). The frequency of females was significantly greater than males in dental caries and alveolar resorption, and conversely in dental calculus (Table 2). The severity of dental wear showed little sex difference (Table 4).

\section{Oral disease and the social environment}

In the Bunun tribe, recent immigrations led to a widespread area of residence in the mountains of Middle Taiwan (Mabuchi, 1954). The census in 1938 shows that there were 4698 individuals in 35 villages at altitudes of between 1500 and $2000 \mathrm{~m}$, and 705 individuals in four villages at altitudes over $2000 \mathrm{~m}$ (Nagasawa, 2002). The Bunun tribe generally engages in slash-and-burn farming in the mountains, as well as hunting and gathering (Miyamoto, 1985). Their slashand-burn farming is focused on millet. The process is as follows. First, they produce arable land through deforestation, switching to a different area every three or five years. The village moves to a new place whenever the fertility of the soil around the village is exhausted (Lu, 1990). In 1937, the itemized income (the homemade products were converted into the corresponding market price) of the Bunun tribe was investigated by the Governor-General of Taiwan. The survey shows that, in the Bunun tribe, agricultural products account for $65 \%$ of the total income, forestry products for $13 \%$, labor and employment for $7 \%$, hunting products for $6 \%$, livestock products for $4 \%$, miscellaneous goods for $3 \%$, and hand crafts for $2 \%$ (Governor-General of Taiwan, 1986). Foxtail millet (Setaria italica) ranks first among the cultivated crops, followed by sorghum (Sorghum bicolor), Chinese millet (Panicum miliaceum), ragi (Eleusine coracana), corn (Zea mays), coix (Coix lacryma-jobi var. mayuen), adlay (Coix lacryma-jobi), chenopod (Chenopodium sp.), azuki bean (Vigna angularis), green 
bean (Vigna radiata), cowpea (Vigna sinensis), hyacinth bean (Dolichos lablab), pigeon pea (Cajanus cajan), peanut (Arachis hypogaea), sweet potato (Ipomoea batatas), taro (Colocasia esculenta), dioscorea (Dioscorea alata), sugar cane (Saccharum officinarum), ginger (Zingiber officinale), cayenne pepper (Capsicum annum), tobacco (Nicotiana tabacum), barker's garlic (Allium bakeri), plum (Prunus salicina), citrus, banana (Musa sapientrum), ramie (Boehmeria nivea, kalib), and gourd (Lagenaria siceraria) (Governor-General of Taiwan, 1986). It is common for large amounts of millet to be piled almost to the ceiling inside a Bunun house, since they are culturally prone to showing off the amount of millet grain they own (Governor-General of Taiwan, 1986).

Considering the relation between oral pathology and subsistence patterns demonstrated by the previous studies (e.g. Turner, 1979; Powell, 1985; Lukacs, 1989; Walker and Erlandson, 1986; Walker and Hewlett, 1990; Larsen, 1997; Pechenkina et al., 2002; Temple and Larsen, 2007; Oyamada et al., 2010), the relatively high degree of dental caries prevalence among the Bunun assemblage is parallel to the expectation based on their subsistence pattern, which is focused on foxtail millet (Miyamoto, 1985; Governor-General of Taiwan, 1986; Lu, 1990). There are two cultivars of foxtail millet: non-glutinous millet (uruchi-awa) and glutinous millet (mochi-awa). The latter variety is cultivated in Taiwan, and it suitable for making mochi (millet cake), chimaki (millet dumplings wrapped in bamboo leaves), and certain types of alcohol (Crawford, 2006). In my experience (K.O. stayed in north China and Taiwan for five years in total), boiled millet meal is much stickier in Taiwan compared to that in north China. Glutinous millet could be more cariogenic than non-glutinous millet because of the difference in its adhesiveness to the tooth crown and root. Compared to the Bunun tribe studied here, lower caries frequencies were shown in the Chinese Neolithic groups who also depended on foxtail millet cultivation (Pechenkina et al., 2002; Okazaki et al., in preparation). Although little comparative study between the recent Taiwanese aboriginal and the Chinese Neolithic groups has been done, since their living environments and time periods are so different, the difference in caries frequency might be partly related to the difference in the sort of foxtail millet between that grown in Taiwan and that grown in north China.

We want to note two points that link the results of this study to the subsistence pattern of the Bunun tribe. First, the subsistence pattern of the Bunun tribe may have changed from the 1920 s to the 1940 s due to the control by the Governor-General of Taiwan. After several armed uprisings by the Bunun people up to 1934, the residence of all subgroups of the Bunun tribe was dealt with as a special administrative zone, and the Governor-General of Taiwan forced the Bunun to move to lower-altitude locations more easily reached by road in order to control them (Nagasawa, 2002). The group examined in the present study was forced to migrate to Bahoan village in 1919 or 1921 by order of the Governor-General of Taiwan. The research report on the history of Bahoan village done by the present local administration mentions that the villagers mostly preserved their traditional subsistence pattern (millet agriculture and hunting- gathering) at least until the $1950 \mathrm{~s}$, even though the Japanese Governor-General of Taiwan recommended that the villagers cultivate wet rice instead of foxtail millet (Wanrong Administration, personal communication). The possibility cannot be denied, however, that the villagers bought some cariogenic foods from peddlers, since some of them earned money by selling their agricultural products and hunted game (Wanrong Administration, personal communication). However, a full-scale change in the Bunun's diet occurred at a much later period. Previous studies on the dental health of the living Bunun people suggest that changes in the traditional dietary habits during the late 1970s explain the abrupt deterioration in oral health (Liu, 1977; Fukutome, 1982; Ozumi, 1983; Miyazaki and Takehara, 1988). Therefore, the enforced migration under the control of the GovernorGeneral of Taiwan might have indirectly affected the diet of the villagers, but the degree should not be significant.

A second point linking the results of this study to the subsistence pattern of the Bunun tribe is that since the tribe regards millet as a culturally special meal, the possibility cannot be denied that consuming millet was mostly limited to ceremonies (not daily food), and that most of the millet grains were just kept inside the house as a symbol of the family's wealth. The stable isotope analysis conducted by Yoneda et al. (2008) indicates that the diet of the Bunun people scores in the middle range between $\mathrm{C} 4$ vegetables and $\mathrm{C} 3$ vegetables. The $\mathrm{C} 4$ vegetables, which include millet, are not so dominant. The $\mathrm{C} 3$ vegetables, which might be sweet potato, banana, sugar cane, and the like, were also consumed in considerable quantity. The high proportion of vegetable foods consumed could lead to high morbidity in dental caries.

The high morbidity in both alveolar resorption and calculus accretion among the Bunun assemblage seems to be very understandable from a clinical viewpoint (Hillson, 1996). Today, most dentists advise the removal of calculus, because the coarseness on the surface of calculus accretion can produce spaces for the propagation of bacteria that can cause periodontal disease (Hillson, 1996). A relatively high frequency of both alveolar resorption and calculus accretion has been repeatedly demonstrated in the past societies of Southeast Asia (Pietrusewsky and Tsang, 2003; Douglas, 2006; Pietrusewsky and Ikehara-Quebral, 2006). Pietrusewsky and Tsang (2003) showed a significantly higher frequency of both alveolar resorption and calculus accretion compared to AMTL, dental caries, and periapical abscess in the skeletal assemblage from the Shi-san-hang site of the prehistoric Iron Age in northern Taiwan. Pietrusewsky and Tsang suggest that the chewing of betel nuts could lead to a more alkaline oral environment, which might explain the significantly higher frequency of both alveolar resorption and calculus accretion. The chewing of betel nuts (Areca catechu) in combination with leaves (Piper betel) and/or lime paste (calcium hydroxide) is a ubiquitous habit in Southeast Asia and the Pacific today. Although the proportion of chewers in Taiwan during Japanese rule is unknown, a questionnaire survey conducted in 1991 showed that, among the Bunun people over the age of $15,37.0 \%$ of males and $26.3 \%$ of the females were chewers at that time (Ko et al., 1992). Therefore, the high morbidity in the indi- 
ces related to periodontal disease of the sample studied here could be attributed to a more alkaline oral environment due to the chewing of betel nuts, the same as the other prehistoric groups in Southeast Asia.

Except for calculus accretion, smoking tobacco could also lead to an increase in alveolar resorption. Smoking is clinically regarded as a strong risk factor for periodontal disease (e.g. Bergstrom, 2004). The smoking habit is widespread among the Bunun tribe: they cultivate tobacco themselves, the males and females generally begin to smoke at the age of 12 or 13 years, and they always carry a pipe with them (Yuasa, 2009). This heavy reliance on smoking could contribute to the poor oral health of the Bunun tribe.

\section{Sex difference of oral disease prevalence}

The degree of sex difference in caries prevalence among the Bunun assemblage (male $12.0 \%$, female $17.6 \%$ ) is considerably greater compared to that of other Asian groups in past societies reported by Lukacs and Thompson (2008) (male average $8.1 \%$, female average $10.9 \%$ ). Therefore, it appears unlikely that the biological factors described above exclusively led to the sex-specific caries prevalence of the Bunun assemblage. Cultural factors should also be considered.

The Bunun tribe is well known for their rigid personalities, especially as regards social rules (Miyamoto, 1985). For example, the Bunun have a typical patriarchal society, and individual economic activities (e.g. the role during hunting and the share of game) and the regulations of the ceremonial activities related to millet cultivation are strictly decided according to the classification of a particular patrilineal kin group (Mabuchi, 1974). The sexual division of labor is also very distinct: females and children take part in gathering and preparing vegetable foods, while males go hunting (Yuasa, 2009). This rigorous distinction between males and females is clearly expressed at the highly significant ear shooting ceremony: females are prohibited from participating in the ceremony or even approaching shooting instruments before and during the ceremony, at which boys shoot at deer carcasses brought in by male hunters. Considering that the Bunun males often dressed and ate game on the spot during hunting (Yuasa, 2009), the ratio of consumed meat could be higher in males than females. Furthermore, females tend to snack during cooking (Walker and Hewlett, 1990). Bunun females traditionally have the responsibility to make millet wine, and they often chew millet grains to aid the fermentation (The Association for Researching Taiwanese Aboriginals by the Governor-General of Taiwan, 1921; Chang et al., 2011). These activities could repeatedly decrease the $\mathrm{pH}$, so that the oral environment changes to being more cariogenic.

The variation in the pattern of sex difference among the occurrence of dental caries, alveolar resorption, and calculus accretion prevalence in the Bunun assemblage is difficult to explain, and multiple factors might cause it. Regarding the inversion of the pattern in sex difference between the dental caries and the calculus accretion prevalence, it could be logically explained by noting that the former is a process of demineralization on the tooth surface, while the latter is a process of mineralization, and the two conditions should therefore be mutually exclusive (Manji et al., 1989). A more alkaline oral environment due to less frequent snacking between meals and/or more frequent chewing of betel nuts could lead to higher calculus accretion prevalence in males of the Bunun tribe. The alveolar resorption prevalence is higher, while the calculus accretion prevalence is lower in females of the Bunun tribe. Considering the strong correlation between calculus accretion and periodontal disease as discussed above, this lack of consistency in the pattern of sex difference between calculus accretion and alveolar resorption is unexpected. The previous studies using clinical data suggest there are multiple factors contributing to periodontal disease, including smoking, diabetes, and the stresses related to the female life history (menstruation, pregnancy, delivery, lactation, and menopause) (Sooriyamoorthy and Gower, 1989; Genco, 1996). Among these factors, calcium deficiency and hormone (estrogens and progesterone) balance changes triggered by female life history might lead to sex differences in alveolar resorption prevalence (Sooriyamoorthy and Gower, 1989; Shoji et al., 2007), although we cannot examine this possibility.

In conclusion, the oral environments of the recent Bunun tribe were characterized by a high morbidity in dental caries, alveolar resorption, and calculus accretion. Based on cultural anthropological records, the carbohydrate-rich foods consumed, the chewing of betel nuts, and the heavy smoking habit are suggested to be factors causing this result. Significant sex differences were observed in dental caries, alveolar resorption, and calculus accretion, and the pattern of the differences varied: the frequency of females was higher in dental caries and alveolar resorption, while the inverse was true in calculus accretion. The sex-specific diet and activities, in particular the chewing of millet to produce an alcoholic drink, could be related to the result. It is difficult to explain the inconsistency of the patterns in the sex differences between alveolar resorption and calculus accretion, even though clinical data often show a correlation between them. The factors that are not observed by cultural anthropologists, e.g. hormone balance changes, might also be related to the sex differences. The results of this study will provide the basis for exploring the factors contributing to the oral disease prevalence and the sex differences of Taiwanese prehistoric/historic skeletal assemblages in future studies.

\section{Acknowledgments}

The authors are grateful to Tsai His-Kuei for granting access to the human skeletal collections under his care.

Grant sponsorship: The aim for the top university project 9924044

\section{References}

Association for Researching Taiwanese Aboriginals by the Governor General of Taiwan, The (1921) A Study on the Customs of the Taiwanese Aboriginals. The Association for Researching Taiwanese Aboriginals by the Governor General of Taiwan, Taipei (in Japanese).

Bergstrom J. (2004) Tobacco smoking and chronic destructive periodontal disease. Odontology, 92: 1-8.

Brothwell D.R. (1981) Digging Up Bones. Cornell University Press, Ithaca, NY. 
Bruzek J. (2002) A method for visual determination of sex, using the human hip bone. American Journal of Physical Anthropology, 117: 157-168.

Buikstra J.E. and Ubelaker D.H. (1994) Standards for Data Collection from Human Skeletal Remains. Arkansas Archaeological Survey, Fayetteville.

Chang L.J., Lo S.F., and Hayter M. (2011) Drinking behaviors: the life narratives of indigenous Bunun women in Taiwan. Journal of Nursing Research, 19: 83-93.

Crawford G.W. (2006) East Asian plant domestication. In: Stark M.T. (ed.), Archaeology of Asia. Blackwell Publishing, Malden, pp. 77-95.

Dias G. and Tayles N. (1997) 'Abscess cavity'-a misnomer. International Journal of Osteoarchaeology, 7: 548-554.

Doi N., Takenaka M., Nakahashi T., and Tsai H. (2008) Catalogue of human skeletal remains stored in the physical anthropological laboratory, National Taiwan University College of Medicine. Anthropological Science (Japanese Series), 116: 176181 (in Japanese with English summary).

Domett K. and Tayles N. (2006) Human biology from the bronze age to the iron age in the Mun River valley of northeast Thailand. In: Oxenham M. and Tayles N. (eds.), Bioarchaeology of Southeast Asia. Cambridge University Press, Cambridge, pp. $220-240$.

Douglas M.T. (2006) Subsistence change and dental health in the people of Non Nok Tha, northeast Thailand. In: Oxenham M. and Tayles N. (eds.), Bioarchaeology of Southeast Asia. Cambridge University Press, Cambridge, pp. 191-219.

Fujita H., Asakura K., and Ogura M. (2007) Age- and sex-related dental caries prevalence in Japanese from the Jomon period. Journal of Oral Biosciences, 49: 198-204.

Fukutome S. (1982) An epidemiological study of tooth and periodontal diseases of Ami and Bunun living in Taiwan Highlands. Kyushu-Shika-Gakkai-zasshi, 36: 678-689 (in Japanese with English summary).

Genco R.J. (1996) Current view of risk factors for periodontal diseases. Journal of Periodontology, 67: 1041-1049.

Governor-General of Taiwan (1986) The Research Report on the Taiwanese Aboriginals (Takasago Tribes), 4. Shonandou Publisher, Tokyo (in Japanese).

Hillson S.W. (1996) Dental Anthropology. Cambridge University Press, Cambridge.

Hillson S.W. (2001) Recording dental caries in archaeological human remains. International Journal of Osteoarchaeology, 11: 249-289.

Kaifu Y., Kasai K., Townsend G.C., and Richards L.C. (2003) Tooth wear and the 'design' of the human dentition: a perspective from evolutionary medicine. American Journal of Physical Anthropology, 122: 47-61.

Ko Y., Chiang T., Chang S., and Hsieh S. (1992) Prevalence of betel quid chewing habit in Taiwan and related sociodemographic factors. Journal of Oral Pathology \& Medicine, 21: 261-264.

Larsen C.S. (1997) Bioarchaeology: Interpreting Behavior from the Human Skeleton. Cambridge University Press, Cambridge.

Liu K.L. (1977) Dental condition of two tribes of Taiwan aborigines-Ami and Atayal. Journal of Dental Research, 56: 117127.

Lovejoy C.O., Meindl R.S., Pryzbeck T.R., and Mensforth R.P. (1985) Chronological metamorphosis of the auricular surface of the ilium: a new method for the determination of adult skeletal age at death. American Journal of Physical Anthropology, 68: 15-28.

Lu Q. (1990) The Social Change and Traditional Culture of the Bunun Tribe. Chengwen Publishing, Taipei (in Chinese).

Lubell D., Jackes M., Schwarcz H., Knyf M., and Meiklejohn C. (1994) The Mesolithic-Neolithic transition in Portugal: isotopic and dental evidence of diet. Journal of Archaeological Science, 21: 201-216.
Lukacs J.R. (1989) Dental paleopathology: methods for reconstructing dietary patterns. In: Iscan M.Y. and Kennedy K.A.R. (eds.), Reconstruction of Life from the Skeleton. Alan R. Liss, New York, pp. 261-286.

Lukacs J.R. and Largaespada L. (2006) Explaining sex differences in dental caries rates: saliva, hormones and 'life history' etiologies. American Journal of Human Biology, 18: 540-555.

Lukacs J.R. and Thompson L.M. (2008) Dental caries prevalence by sex in prehistory: magnitude and meaning. In: Irish J.D. and Nelson G.C. (eds.), Technique and Application in Dental Anthropology. Cambridge University Press, Cambridge, pp. 136-177.

Mabuchi T. (1954) Migration and distribution of the Formosan aborigines. Japanese Journal of Ethnology, 18(1-2): 123-154 (in Japanese with English summary).

Mabuchi T. (1974) The kinship terminology of the both Bunun and Tsou tribe. In: Mabuchi T. (ed.), The Collected Work of Toichi Mabuchi. Shakaishiso Publisher, Tokyo, pp. 61-91 (in Japanese).

Manji F., Fejerskov O., Baelum V., and Nagelkerke N. (1989) Dental calculus and caries experience in 14-65 year olds with no access to dental care. In: Ten Cate J.M. (ed.), Recent Advances in the Study of Dental Calculus. IRL Press at Oxford University Press, Oxford, pp. 223-234.

Meindle R.S. and Lovejoy C.O. (1985) Ectocranial suture closure: a revised method for the determination of skeletal age at death based on the lateral-anterior sutures. American Journal of Physical Anthropology, 68: 57-66.

Meindle R.S., Lovejoy C.O., and Mensforth R.P. (1985) A revised method of age determination using the os pubis, with a review and tests of accuracy of other current methods of pubic symphyseal aging. American Journal of Physical Anthropology, 68: $29-45$.

Miyamoto N. (1985) The Taiwanese Aboriginals-Memoirs of my Ethnographical Researches. Rokkou Publisher, Tokyo (in Japanese).

Miyazaki H. and Takehara T. (1988) Prevalence of dental caries in Taiwan aboriginal children-Bunun, Paiwan, Rukai, Ami, and Yami tribes. Australian Dental Journal, 33: 226-230.

Nagasawa T. (2002) 2.3. Bunun tribe. In: Shung Ye Taiwan Aborigines Research Group in Japan (ed.), The Summary of the Studies on Taiwanese Aboriginals. Fukyo-sha, Tokyo, pp. 160-164 (in Japanese).

Nakahashi T. (2008) Ritual tooth extraction in the human skeletal remains stored in the National Taiwan University. Anthropological Science (Japanese Series), 116: 171-175 (in Japanese with English summary).

Okazaki K., Wei D., and Zhu H. (in preparation) Change in oral disease of millet agriculturalists from the Middle Neolithic to the Sixteen Kingdoms period in the northern "Great Wall" region of China.

Oxenham M., Cuong N.L., and Thuy N.K. (2006) The oral health consequences of the adoption and intensification of agriculture in Southeast Asia. In: Oxenham M. and Tayles N. (eds.), Bioarchaeology of Southeast Asia. Cambridge University Press, Cambridge, pp. 263-289.

Oyamada J., Igawa K., Manabe Y., Kato K., Matsushita T., Rokutanda A., and Kitagawa Y. (2010) Preliminary analysis of regional differences in dental pathology of early modern commoners in Japan. Anthropological Science, 118: 1-8.

Ozumi T. (1983) An epidemiological study of incidence of dental caries in deciduous teeth and gingival disease of Taiwan aboriginal children. Kyushu-Shika-Gakkai-zasshi, 37: 894906 (in Japanese with English summary).

Pechenkina E.A., Benfer R.A., and Wang Z. (2002) Diet and health changes at the end of the Chinese Neolithic: the Yangshao/Longshan transition in Shanxi province. American Journal of Physical Anthropology, 117: 15-36.

Phenice T.W. (1969) A newly developed visual method of sexing the os pubis. American Journal of Physical Anthropology, 30: 
297-301.

Pietrusewsky M. and Douglas M.T. (2001) Intensification of agriculture at Ban Chiang: is there evidence from the skeletons? Asian Perspectives, 40: 157-178.

Pietrusewsky M. and Ikehara-Quebral R. (2006) The bioarchaeology of the Vat Komnou cemetery, Angkor Borei, Cambodia. Indo-Pacific Prehistory Association Bulletin, 26: 86-97.

Pietrusewsky M. and Tsang C. (2003) A preliminary assessment of health and disease in human skeletal remains from Shi San Hang: a prehistoric aboriginal site on Taiwan. Anthropological Science, 111: 203-223.

Powell M.L. (1985) The analysis of dental wear and caries for dietary reconstruction. In: Gilbert R.I. and Mielke J.H. (eds.), The Analysis of Prehistoric Diets. Academic Press, Orlando, FL, pp. 307-338.

Sakashita R., Inoue M., Inoue N., Pan Q., and Zhu H. (1997) Dental disease in the Chinese Yin-Shang period with respect to relationships between citizens and slaves. American Journal of Physical Anthropology, 103: 401-408.

Shoji K., Ohtsuka-Isoya M., Shimauchi H., and Shinoda H. (2007) Effects of lactation on alveolar bone loss in experimental periodontitis. Journal of Periodontology, 78: 152-156.

Sooriyamoorthy M. and Gower D.B. (1989) Hormonal influences on gingival tissue: relationship to periodontal disease. Journal of Clinical Periodontology, 16: 201-208.

StatSoft Inc. (1996) User's manual for STATISTICA. StatSoft Japan, Tokyo (in Japanese)

Temple D.H. (2011) Variability in dental caries prevalence between male and female foragers from the late/final Jomon period: implications for dietary behavior and reproductive ecology. American Journal of Human Biology, 23: 107-117.

Temple D.H. and Larsen C.S. (2007) Dental caries prevalence as evidence for agriculture and subsistence variation during the Yayoi period in prehistoric Japan: biocultural interpretations of an economy in transition. American Journal of Physical Anthropology, 134: 501-512.

Todd T.W. (1920) Age changes in the pubic bone: 1. The white male pubis. American Journal of Physical Anthropology, 3: 467-470.

Turner C.G. (1979) Dental anthropological indications of agriculture among the Jomon people of central Japan: X. Peopling of the Pacific. American Journal of Physical Anthropology, 51: 619-636.

Walker P.L. (2005) Greater sciatic notch morphology: sex, age, and population differences. American Journal of Physical Anthropology, 127: 385-391.

Walker P.L. and Erlandson J.M. (1986) Dental evidence for prehistoric dietary change on the northern Channel Islands, California. American Antiquity, 51: 375-383.

Walker P.L. and Hewlett B.S. (1990) Dental health, diet, and social status among Central African foragers and farmers. American Anthropologist, 92: 383-398.

Yoneda M., Mukai H., and Sai H. (2008) Isotopic analysis on human skeletons from prehistoric sites and recent Bunun population of Taiwan. Anthropological Science (Japanese Series), 116: 161-170 (in Japanese with English summary).

Yuasa H. (2009) Segawa's Illustrated Ethnography of Indigenous Formosan People, the Bunun. SMC Publishing, Taipei (in Chinese, English and Japanese). 